\title{
The (Non)Performance Of Kiplinger's Expert Recommendations
}

Richard Borghesi, University of South Florida, USA

Thomas Pencek, University of South Florida, USA

\begin{abstract}
We examine the performance of 1,572 stock recommendations published over the past 10 years by Kiplinger's Personal Finance magazine. Kiplinger's picks earned a risk-adjusted mean abnormal monthly return of $-2.58 \%$ over the 6-month post-pick period. Our analysis indicates that the recommended firms were larger than average, and that the non-risk-adjusted returns of these stocks exceeded market returns prior to being selected. The poor post-pick performance cannot be attributed to a small subset of stocks or to a particular time frame. Instead, the experts appear to significantly underperform throughout much of the period examined. Our findings suggest that the experts of some popular investment periodicals may bias their analyses in favor of hot stocks to appeal to the interests of naïve subscribers.
\end{abstract}

Keywords: investment advice, market efficiency, experts

\section{INTRODUCTION}

C1 Ciplinger's Personal Finance (henceforth Kiplinger's) is a widely-available periodical that provides its readers with investment advice. The magazine has a readership of roughly 800,000 per month, targets affluent professionals, and provides its readers with stock picks along with brief explanations about why each investment represents a valuable opportunity. Offering stock recommendations is nearly ubiquitous among similar financial publications. For example, The Wall Street Journal's "Heard on the Street," BusinessWeek's "Inside Wall Street," and Barron's Magazine's "Up and Down Wall Street," "Investment News \& Views," and Roundtable each provide investors with stock analyses and predictions.

The post-recommendation stock performances of popular press outlets have attracted the attention of finance researchers. Many have examined whether stock prices are affected by the recommendations themselves and/or attempted to determine whether experts' recommendations are valuable to investors. Results are mixed, with some researchers documenting positive abnormal returns and others finding no significant relationship between advice and performance.

Among the body of work finding that experts' picks provide value are a series of papers examining the “Timeliness Ranking System" published by Value Line. Copeland and Mayers (1982), Hall and Tsay (1988), and Pawlukiewicz and Preece (1991) found that stocks classified as a "one" outperform the market. In a similar vein, Trahan and Bolster (1995) examined 144 buy recommendations made in a variety of columns for Barron's Magazine. They found significant positive returns on the day of magazine distribution and from day 0 through day 16 , and determined that abnormal returns were more pronounced for recommendations on smaller firms.

Results from several others concur that following experts' advice can produce profitable outcomes. Sant and Zaman (1996) studied recommendations made in the BusinessWeek column "Inside Wall Street" from the period 1976 through 1988. They examined 40 negative, 88 inconclusive, and 328 positive recommendations and found significant positive returns in the three days surrounding the publication date and also for those stocks that had positive recommendations. Among the stocks that received negative recommendations, no significant excess returns were identified. 
Schadler and Eakins (2001) studied the performance of stocks selected for Merrill Lynch's "focus" picks. The authors found abnormal same-day returns and abnormal returns in the two days in advance of the announcement. Habegger and Pace (2008) examined the recommendations made by The Wall Street Journal's "SmartMoney Stock Screen," and found abnormal returns of 1.17\% for positive recommendations and $-5.85 \%$ for short recommendations.

However, not all studies conclude that following the experts' advice enables one to beat the market. For instance, Hemand, Desai, and Jain (1995) studied the recommendations made by the participants in Barron's Magazine's Roundtable. The Roundtable is composed primarily of invited financial analysts and fund managers. The authors analyzed a sample of 1,599 buy recommendations and 152 sell recommendations and found significant abnormal returns from recommendation day to publication day. However, they determined that the post-publication returns on buy recommendation were no different than zero, so the advice was of little use to those who subscribed.

Likewise, Brody and Rees (1995) looked at 239 recommendations made by Money and Changing Times magazines and found no evidence of excess returns. In addition, Jaffe and Mahoney (1999) followed the advice of investment newsletters of Hulbert Financial Digest and found that the advice did not enable one to outperform the market. Furthermore, Dewally (2003) studied 876 recommendations from internet sites. He found that these stocks were generally recommended after a run up in price, and that neither the short- nor long-term performance was different than that of the market.

The purpose of our paper is to quantify the value of the expert recommendations provided by Kiplinger's. Results suggest that in the 6-month span after these recommendations are published, investors who took Kiplinger's expert advice would have underperformed the market by an average of $2.58 \%$ per month.

\section{DATA AND METHODOLOGY}

We collect data on the 1,627 recommendations made by Kiplinger's experts from January 1999 through December 2008. CRSP and Compustat data are available for 1,572 of these picks. ${ }^{1}$ We examine pick performance over four time frames: $(-6,0),(-1,0),(0,1)$ and $(0,6)$. These represent the monthly stock returns six months prior to, one month prior to, one month after, and six months after each recommendation, respectively.

We begin by contrasting the median and mean pre-and post-pick returns. If market prices are efficient and experts are rational, then there is no obvious reason to expect pre-pick returns to be abnormally high, or for postpick returns to be abnormally low. If we observe otherwise, then it would be desirable to understand why. We propose that a portion of Kiplinger's subscribers are likely to be 'naïve' in that they fail to consider the higher risk associated with stocks that produce higher returns. We also suggest that experts may prefer to discuss/recommend 'hot' stocks because naïve subscribers are intrigued by discussions about such securities and/or become overeager at the thought of owning them. We define a hot stock as one having a non-risk-adjusted return that significantly exceeds the return of a value-weighted market index. If we observe that pre-pick returns are exceptionally high, and that there is subsequent performance decline after publication, one could reasonably infer that the experts tend to pick hot stocks, the returns of which often subsequently experience reversals.

To test our hypotheses, we calculate abnormal returns using variety of event study models. Four different specifications are utilized since no single one will enable us to explain the experts' motivations in picking this particular collection of stocks and also permit us to describe the experts' talent. The proposed models are as follows: ${ }^{2}$

\footnotetext{
1 The remaining stocks were traded on foreign or OTC exchanges for which no data are available, or else were pre-IPO recommendations for which no prior returns or betas are available.

${ }^{2}$ We essentially follow Neumann and Kenny (2007) by employing Model 1, Model 2, and Model 3, while Model 4 utilizes the Fama-French 3-Factor as in Barber and Lyon (1997) and Barber, Lehavy, McNichols, and Trueman (2003), among others.
} 


$$
\begin{aligned}
& A R_{i, t}=R_{i, t}-R_{i, t \text { (average })} \\
& A R_{i, t}=R_{i, t}-R_{\text {market }, t} \\
& A R_{i, t}=R_{i, t}-\left[\alpha_{i}+\beta_{i}\left(R_{\text {market }, t}\right)\right] \\
& A R_{i, t}=R_{i, t}-\left[\alpha_{i}+\beta_{3 i}\left(R_{\text {market }, t}\right)+\beta_{S i}\left(S M B_{i, t}\right)+\beta_{V i}\left(H M L_{i, t}\right)\right]
\end{aligned}
$$

In the proposed specifications, $A R_{i, t}$ is the abnormal return of stock $i$ in month $t, R_{i, t}$ is the observed return of each recommended stock $i$ over $t$ months, $R_{i, t(\text { average })}$ is each stock's mean observed return over the prior $t$ months, and $R_{\text {market, } t}$ is the return on the CRSP value-weighted index.

We begin the analysis using Model 1, which enables us to measure whether pre-pick returns differ from post-pick returns. If post-pick returns are significantly lower, results would indicate that the experts pick stocks which fail to continue performing as they had in prior months. However, without an independent returns benchmark, it would be difficult to understand why. So, we employ Model 2 to benchmark the performance of each stock relative to that of an 'average' stock during both the pre- and post-pick periods. If we observe that the prepick performance of recommended stocks exceeds that of the market, then it may be reasonable to infer that the experts tend to favor recommending hot stocks, possibly in order to capitalize on reader interest. And, if post-pick returns are less than those of the market, then evidence would suggest that these hot stocks tend to experience subsequent reversals.

Finally, we employ Model 3 and Model 4 to compute risk-adjusted abnormal returns, which provide a better sense of the 'true' value provided by the experts. If post-pick returns are found to be below risk-adjusted expectations, then the experts' picks are value-destroying. Model 3 represents the CAPM, while Model 4 represents a Fama-French 3-Factor Model. Prior research, beginning with Fama and French (1992), shows that the stocks of firms having small market capitalizations and those with high book values relative to market values provide higher returns, yet these excess returns are not fully captured by the standard CAPM model.

To obtain the betas in Model 3 and Model 4, we estimate the relationship between monthly CRSP valueweighted returns and each stock's monthly returns over the 6-month period prior to recommendation. To estimate $S M B_{i, t}\left(H M L_{i, t}\right)$, we calculate the median market-value-of-equity (book-to-market ratio) in each month $t$ for all firms in the CRSP database. Those firms below the median are classified as small (low), and those above the median are classified as big (high). We then difference the monthly value-weighted mean returns of stocks within each classification to calculate $S M B_{i, t}\left(H M L_{i, t}\right)$.

\section{RESULTS}

Table 1 presents summary statistics describing the sample set of observations. On average, Kiplinger's experts tend to recommend the stocks of relatively large firms, so the additional size correction in Model 4 will be important. The top rows of Table 2 contain the median and mean monthly returns before and after Kiplinger's publishes its recommendations. Results indicate that pre-pick returns are significantly positive, yet post-pick returns are significantly negative. The mean monthly return in the six (one) months prior to publication is $1.12 \%(0.02 \%)$, while that in the six (one) months after publication is $-1.87 \%(-0.34 \%){ }^{3}$ Beneath these observed monthly returns, we report results from each of the four proposed event study models which may help to understand this potentially interesting trend.

\footnotetext{
${ }^{3}$ The exact date at which the experts arrived at their picks is unclear. It may be that picks are submitted to the magazine several weeks in advance of the magazine cover's date of publication. Therefore, stock returns may have already begun a reversal before publication. This may help explain why the difference between 1-month pre- and post-pick returns is less than the difference between 6-month pre- and post-pick returns.
} 
Table 1: Data Summary Statistics

This table describes 1,572 Kiplinger's stock picks from January 1999 through December 2008, and all stocks in the merged CRSP/Compustat database (Market) over the same time period.

\begin{tabular}{|c|c|c|c|c|c|}
\hline \multirow{3}{*}{ Market } & & Beta & Assets (\$M) & MVE (\$M) & Book/Market \\
\hline & Median & - & 212 & 147 & 0.47 \\
\hline & Mean & - & 8,621 & 2,787 & 0.51 \\
\hline \multirow{2}{*}{ Kiplinger's } & Median & 0.96 & 4,921 & 6,033 & 0.32 \\
\hline & Mean & 1.20 & 48,831 & 30,427 & 0.88 \\
\hline
\end{tabular}

Table 2: Pre- and Post-Pick Returns

This table shows pre- and post-pick monthly returns for 1,572 of Kiplinger's stock picks from January 1999 through December 2008. Associated $p$-Values are given in parentheses.

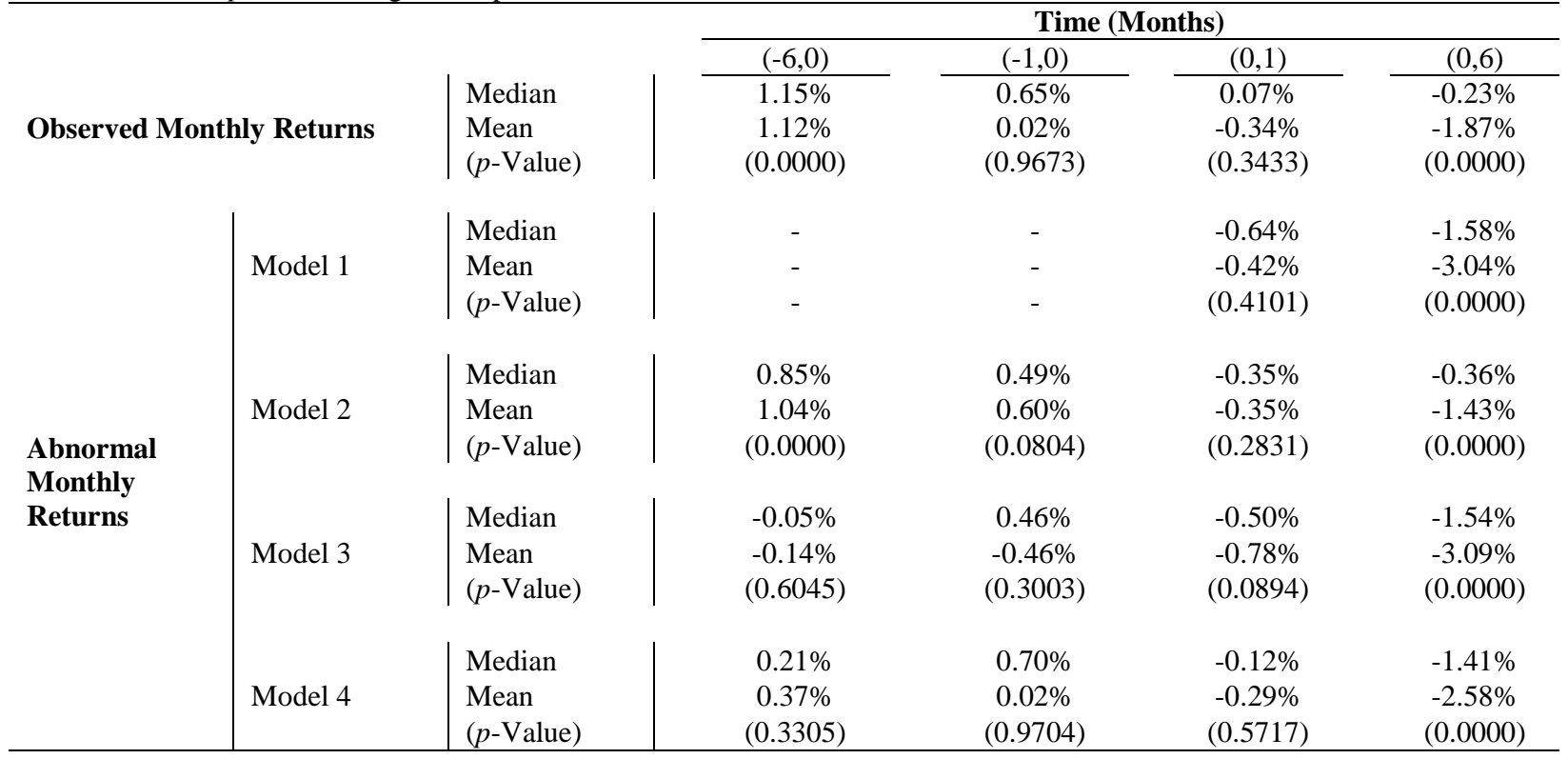

Model 1 captures post-pick performance relative to pre-pick performance, and illustrates that there is a significant decline in performance after publication; the 6-month post-pick returns are significantly less than the 6month pre-pick returns. Moving forward, if we also observe that the pre-pick returns are greater than the market average, then results would be consistent with the proposition that the experts picked hot stocks that subsequently experienced reversals.

Indeed, results from Model 2 show that the selected stocks outperform the market prior to publication. The mean 6- and 1-month abnormal returns are $1.04 \%$ and $0.60 \%$, respectively, and each is significantly greater than zero. However, these same stocks perform far worse than the market after publication. The mean 6-month postpick abnormal return is $-1.43 \%$, which is significantly less than zero at the $1 \%$ level. Contrasting the pre- and postpick returns, our interpretation is that Kiplinger's experts tend to pick stocks that appear to outperform the market over the prior one and six months. These formerly hot stocks then experience reversals and underperform relative to the market. Results thus far are consistent with the idea that Kiplinger's experts favored hot stocks, possibly to maximize interest among naïve readers, and at the expense of being value-destroying. However, before drawing conclusions about the talent level of the experts, we must incorporate standard corrections for risk.

Model 3 controls for market risk, while Model 4 additionally controls for size and value effects. Examining results from Model 3, we observe that pre-pick risk-adjusted performance does not differ from expectations. In other words, the recommended stocks did not actually outperform the market before they were 
selected. However, the 1-month (6-month) post-pick mean abnormal return is $-0.78 \%(-3.09 \%)$, which is significantly below zero at the $10 \%(1 \%)$ level. Thus, the experts chose stocks that exhibited normal risk-adjusted performance, but these picks resulted in poor risk-adjusted performance for subscribers who followed Kiplinger's advice. Model 4 shows that the recommended stocks also significantly underperform risk-, size-, and value-adjusted expectations. While the 1-month post-pick performance is not different than expected, the 6-month post-pick mean monthly abnormal return is $-2.58 \%$, which is significantly below zero at the $1 \%$ level.

Synthesizing results from each of the four models, our interpretation is that Kiplinger's experts tend to favor glamour stocks - those that appeared to be hot in a naïve, non-risk-adjusted sense - perhaps because printing articles that discuss hot stocks generates more reader interest. And, while the pre-pick performance of these stocks was no different than expected given their risk, the post-pick risk-adjusted performance was reliably worse than expected. So, the experts' picks were actually value-destroying to subscribers.

To examine the attractiveness (and subsequent performance) of the expert picks from the viewpoints of naïve and sophisticated investors, we next calculate within each of the four proposed time frames the proportion of picks that have negative abnormal returns. We utilize Model 2 (which represents the interests of naïve investors, who care about hot stocks) and Model 4 (which accounts for the deeper understanding of the relationship between risk and return among sophisticated investors).

We propose that the experts have an incentive to pick stocks that excite the interests of naïve investors. If hot stocks are preferred, then we expect to observe that relatively few stocks experience negative non-risk-adjusted abnormal returns in pre-pick periods. However, this would not necessarily be the case in post-pick periods, especially if the selected stocks tend to experience reversals after periods of abnormally high returns. Furthermore, we expect to find that a lower percentage of picks have positive risk-adjusted abnormal returns in the months prior to selection. By definition, such performance is irrelevant to naïve investors.

Results of a corresponding analysis are presented in Table 3. Indeed, we observe that only $39.41 \%$ of stocks have non-risk-adjusted negative abnormal returns in the 6-month pre-pick period. Yet, as expected, the majority of these stocks subsequently experience negative abnormal returns. The difference between these pre- and post-pick proportions is significant at the $1 \%$ level. After risk-adjusting, 51.28\% of stocks experience negative abnormal returns in the 6-month pre-pick period. This is consistent with our theory that Kiplinger's picks target the interests of naïve investors; there is no incentive for the experts to pick stocks that surpass risk-adjusted expectations since few subscribers would be attuned.

To better understand why Kiplinger's experts make such poor selections, we next examine the distribution of their picks across exchanges and over time. Table 4 summarizes the outcomes of 1,489 expert picks which have data available throughout the full 6-month post-pick return period. Of these recommendations, 995 stocks traded on the New York Stock Exchange, 483 on NASDAQ, 10 on the American Stock Exchange, and one on Arca.

In Table 4, we use Model 4 to calculate mean abnormal returns. While there is some variation across years and exchanges, the poor performance of Kiplinger's experts is not the result of an isolated event or confined within a single time period. Instead, performance is poor throughout much of the period examined. Experts' NYSE picks underperformed risk-adjusted expectations by $1.22 \%$ per month, which is significant at the $1 \%$ level. In addition, NYSE returns are significantly less than expected in four of the 10 years examined. A similar result holds when looking at the Kiplinger's NASDAQ performance, where its experts significantly also underperformed in four of the years, and earned a risk-adjusted abnormal return of $-5.49 \%$ per month on average. 
Table 3: Proportion of Picks Having Negative Abnormal Returns

This table shows the proportion of abnormal returns (AR) for the 1,572 recommendations that are negative for each of the four event-centered periods. Model 2 (Model 4 ) represents outcomes from the viewpoint of naïve (sophisticated) investors.

\begin{tabular}{|c|c|c|c|c|c|c|c|c|c|c|c|c|}
\hline \multirow{3}{*}{ Year } & \multicolumn{6}{|c|}{ Model 2} & \multicolumn{6}{|c|}{ Model 4} \\
\hline & \multicolumn{2}{|c|}{$\begin{array}{c}\text { Proportion } \\
\text { Negative AR } \\
\end{array}$} & Difference & \multicolumn{2}{|c|}{$\begin{array}{c}\text { Proportion } \\
\text { Negative AR } \\
\end{array}$} & \multirow[t]{2}{*}{ Difference } & \multicolumn{2}{|c|}{$\begin{array}{c}\text { Proportion } \\
\text { Negative AR }\end{array}$} & \multirow[t]{2}{*}{ Difference } & \multicolumn{2}{|c|}{$\begin{array}{c}\text { Proportion } \\
\text { Negative AR } \\
\end{array}$} & \multirow[t]{2}{*}{ Difference } \\
\hline & $(-6,0)$ & $(0,6)$ & & $(-1,0)$ & $(0,1)$ & & $(-6,0)$ & $(0,6)$ & & $(-1,0)$ & $(0,1)$ & \\
\hline 1999 & $47.37 \%$ & $56.96 \%$ & $-9.59 \%$ & $48.57 \%$ & $42.50 \%$ & $6.07 \%$ & $54.05 \%$ & $59.02 \%$ & $-4.96 \%$ & $48.39 \%$ & $46.77 \%$ & $1.61 \%$ \\
\hline 2000 & $44.57 \%$ & $59.36 \%$ & $-14.79 \% * * *$ & $53.15 \%$ & $60.28 \%$ & $-7.13 \% *$ & $52.07 \%$ & $61.66 \%$ & $-9.59 \% * * *$ & $52.53 \%$ & $54.86 \%$ & $-2.33 \%$ \\
\hline 2001 & $32.96 \%$ & $44.98 \%$ & $-12.02 \% * * *$ & $44.69 \%$ & $49.63 \%$ & $-4.94 \%$ & $53.91 \%$ & $58.53 \%$ & $-4.62 \% * *$ & $46.95 \%$ & $54.79 \%$ & $-7.84 \% * *$ \\
\hline 2002 & $33.52 \%$ & $51.93 \%$ & $-18.41 \% * * *$ & $41.44 \%$ & $41.76 \%$ & $-0.32 \%$ & $47.09 \%$ & $51.70 \%$ & $-4.61 \% * *$ & $49.15 \%$ & $45.20 \%$ & $3.95 \%$ \\
\hline 2003 & $34.21 \%$ & $55.84 \%$ & $-21.63 \% * *$ & $39.74 \%$ & $47.44 \%$ & $-7.69 \%$ & $51.32 \%$ & $57.14 \%$ & $-5.83 \%$ & $46.15 \%$ & $50.00 \%$ & $-3.85 \%$ \\
\hline 2004 & $41.67 \%$ & $54.13 \%$ & $-12.46 \% * *$ & $41.28 \%$ & $64.22 \%$ & $-22.94 \% * * *$ & $54.63 \%$ & $56.88 \%$ & $-2.25 \%$ & $53.21 \%$ & $56.88 \%$ & $-3.67 \%$ \\
\hline 2005 & $47.83 \%$ & $58.70 \%$ & $-10.87 \% *$ & $53.57 \%$ & $62.86 \%$ & $-9.29 \% *$ & $40.31 \%$ & $40.31 \%$ & $0.00 \%$ & $48.09 \%$ & $41.98 \%$ & $6.11 \%$ \\
\hline 2006 & $39.71 \%$ & $56.93 \%$ & $-17.23 \% * * *$ & $46.04 \%$ & $51.80 \%$ & $-5.76 \%$ & $53.68 \%$ & $56.93 \%$ & $-3.26 \% * *$ & $49.64 \%$ & $54.68 \%$ & $-5.04 \%$ \\
\hline 2007 & $41.13 \%$ & $44.68 \%$ & $-3.55 \%$ & $43.26 \%$ & $43.26 \%$ & $0.00 \%$ & $57.14 \%$ & $63.57 \%$ & $-6.43 \% * *$ & $56.43 \%$ & $59.29 \%$ & $-2.86 \% * *$ \\
\hline 2008 & $36.49 \%$ & $64.00 \%$ & $-27.51 \% * * *$ & $51.16 \%$ & $49.07 \%$ & $2.09 \%$ & $46.48 \%$ & $56.94 \%$ & $-10.47 \%$ & $50.00 \%$ & $39.22 \%$ & $10.78 \%$ \\
\hline All & $39.41 \%$ & $53.73 \%$ & $-14.32 \% * * *$ & $47.01 \%$ & $51.92 \%$ & $-4.91 \% * * *$ & $51.28 \%$ & $56.66 \%$ & $-5.38 \% * * *$ & $50.16 \%$ & $50.96 \%$ & $-0.80 \%$ \\
\hline
\end{tabular}

* significant at the $10 \%$ level

** significant at the $5 \%$ leve

$* * *$ significant at the $1 \%$ level

Table 4: 6-Month Post-Pick Monthly Abnormal Returns

This table shows Kiplinger's mean 6-month post-pick monthly abnormal returns (AR) and associated $p$-Values. All results are generated from Model 4.

\begin{tabular}{|c|c|c|c|c|c|c|c|c|c|}
\hline \multirow{3}{*}{ Year } & \multicolumn{9}{|c|}{ Exchange } \\
\hline & \multicolumn{3}{|c|}{ NYSE } & \multicolumn{3}{|c|}{ NASDAQ } & \multicolumn{3}{|c|}{ All } \\
\hline & $\mathbf{N}$ & AR & $p$-Value & $\mathbf{N}$ & AR & $p$-Value & $\mathbf{N}$ & AR & $p$-Value \\
\hline 1999 & 51 & $3.24 \%$ & $(0.2295)$ & 28 & $-16.06 \%$ & $(0.0117)$ & 79 & $-3.19 \%$ & $(0.2763)$ \\
\hline 2000 & 148 & $-1.15 \%$ & $(0.3500)$ & 134 & $-10.44 \%$ & (0.0007) & 283 & $-5.42 \%$ & $(0.0006)$ \\
\hline 2001 & 192 & $-2.25 \%$ & $(0.0334)$ & 77 & $-10.62 \%$ & $(0.0000)$ & 269 & $-4.79 \%$ & $(0.0000)$ \\
\hline 2002 & 126 & $-2.48 \%$ & $(0.0294)$ & 54 & $-0.21 \%$ & $(0.9240)$ & 181 & $-1.74 \%$ & $(0.0895)$ \\
\hline 2003 & 54 & $-0.91 \%$ & $(0.4961)$ & 22 & $-3.53 \%$ & $(0.1112)$ & 77 & $-1.50 \%$ & $(0.1826)$ \\
\hline 2004 & 72 & $-1.25 \%$ & $(0.1405)$ & 36 & $-1.27 \%$ & $(0.4852)$ & 109 & $-1.25 \%$ & $(0.1245)$ \\
\hline 2005 & 108 & $1.45 \%$ & $(0.0202)$ & 29 & $0.80 \%$ & $(0.6528)$ & 138 & $1.40 \%$ & $(0.0258)$ \\
\hline 2006 & 95 & $-0.39 \%$ & $(0.5453)$ & 39 & $-1.86 \%$ & $(0.2840)$ & 137 & $-0.88 \%$ & $(0.1949)$ \\
\hline 2007 & 94 & $-1.92 \%$ & $(0.0218)$ & 46 & $-3.62 \%$ & $(0.0289)$ & 141 & $-2.54 \%$ & $(0.0011)$ \\
\hline 2008 & 55 & $-2.78 \%$ & $(0.0519)$ & 18 & $1.84 \%$ & $(0.5260)$ & 75 & $-1.73 \%$ & $(0.1724)$ \\
\hline All & 995 & $-1.22 \%$ & $(0.0006)$ & 483 & $-5.49 \%$ & $(0.0000)$ & 1,489 & $-2.58 \%$ & $(0.0000)$ \\
\hline
\end{tabular}




\section{SUMMARY AND CONCLUSIONS}

Prior research finds mixed results regarding the value of expert stock picks. We examine the performance of 1,572 picks made by the experts at Kiplinger's magazine and find that these recommendations significantly underperform the market. Following Kiplinger's advice, one would have earned a risk-adjusted mean abnormal monthly return of $-2.58 \%$ over the six months after publication. These inferior returns are not skewed by a small set of underperforming stocks. Instead, evidence suggests that the experts consistently picked hot stocks that subsequently experienced pronounced reversals. The coverage bias towards stocks that have experienced recent price run-ups may arise from the magazine's desire to capitalize on the interests of naïve readers, and come at the expense of realized performance.

\section{AUTHOR INFORMATION}

Dr. Borghesi earned a Ph.D. from the University of Florida in 2004 and an MBA from Loyola University Chicago in 1995. His research interests include corporate finance, corruption, market efficiency, and prediction markets, and he has published in Financial Management, the Southern Economic Journal, Finance Research Letters, the Journal of Economics and Business, Applied Financial Economics, Applied Economics, and The Journal of Prediction Markets.

Dr. Pencek earned his D.B.A. in Finance from Mississippi State University in 1988. He received his MBA from Mississippi State University. He received his BS from State University College at Fredonia. At Meredith College, he received the outstanding teacher award in 2003, and was the founder and faculty advisor to the Student Investment Group which invested money for the college. He has presented papers at Academy of Financial Service, Decisions Sciences Institute, Academy of Business Disciplines and Midwest Finance Association. His research interests are investments and efficiency of markets.

\section{REFERENCES}

1. B. Barber and J. Lyon, "Detecting Long-Run Abnormal Stock Returns: The Empirical Power and Specification of Test Statistics," Journal of Financial Economics, (1997), Vol. 43, pp. 341-372.

2. B. Barber, R. Lehavy, M. McNichols, and B. Trueman, "Reassessing the Returns to Analysts' Stock Recommendations," Financial Analysts Journal, (March/April 2003), Vol. 59, No. 2, pp. 88-96.

3. R. Brody and L. Rees, "The Performance of Popular Investment Magazine Stock Analysts," Journal of Applied Business Research, (Winter 1995/1996), Vol. 12, No. 1, pp. 42-48.

4. T. Copeland and D. Mayers, "The Value Line Enigma (1965-1978): A Case Study of Performance Evaluation Issues," Journal of Financial Economics, (November 1982), Vol. 10, No. 3, pp. 289-321.

5. M. Dewally, "Internet Investment Advice: Investing with a Rock of Salt," Financial Analysts Journal, (July/August 2003), Vol. 49, No. 4, pp. 65-77.

6. E. Fama and K. French, "The Cross-Section of Expected Stock Returns," Journal of Finance, (1992), Vol. 47, No. 2, pp. 427-465

7. T. Hall and J. Tsay, "An Evaluation of the Performance of Portfolios Selected From Value Line Rank One Stocks: 1976-1982," Journal of Financial Research, (Fall 1988), Vol. 11, No. 3, pp. 227-240.

8. W. Habegger and R. Pace, "The Investment Value of the Wall Street Journal's Smart Money Stock Screen," International Journal of Business, (Spring 2008), Vol. 13, No. 2, pp. 165-175.

9. S. Hemand, H. Desai and P. Jain, "An Analysis of the Recommendations of the 'Superstar' Money Managers at Barron's Annual Roundtable,” Journal of Finance, (September 1995), Vol. 50, No. 4, pp. $1257-1273$.

10. J.F. Jaffe and J.M. Mahoney, “The Performance of Investment Newsletters," Journal of Financial Economics, (August 1999), Vol. 53, No. 2, pp. 289-307.

11. J. Neumann and P. Kenny, "Does Mad Money Make the Market Go Mad?," The Quarterly Review of Economics and Finance, (2007), Vol. 47, pp. 602-615.

12. J. Pawlukiewicz and D. Preece, "The Impact of Value Line Special Situations Recommendations on Stock Prices: Evidence from the Over-the-Counter Market," The Financial Review, (November 1991), Vol. 26, No. 4, pp. 547-568. 
13. R. Sant and M. Zaman, "Market Reaction to Business Week 'Inside Wall Street' Column: A Self-Fulfilling Prophecy," Journal of Banking and Finance, (1996), Vol. 20, No. 4, pp. 617-643.

14. F. Schadler and S. Eakins, "Merrill Lynch's Focus Stock Picks: A Test of Analysts' Stock Picking Ability," Quarterly Journal of Business and Economics, (Spring 2001), Vol. 40, No. 2, pp. 17-30.

15. E. Trahan and P. Bolster, "The Impact of Barron's Recommendations of Stock Prices," Quarterly Journal of Business and Economics, (Autumn 1995), Vol. 34, No. 4, pp. 3-15. 